\title{
Potential of morpho-physiological traits for identification of drought tolerant bread wheat (Triticum aestivum L.) genotypes under moisture stress and irrigated environment
}

Jashvantlal Manilal Patel ${ }^{1 *}$, Shashikant Kacharabhai Patel ${ }^{1}$, Chirag Rameshbhai Patel ${ }^{1}$, Amrutbhai Shankerlal Patel ${ }^{1}$ and Karen P. Pachchigar ${ }^{2}$

${ }^{1}$ Wheat Research Station, S.D Agricultural University, Vijapur -382 870, India

${ }^{2}$ College of Basic Sciences, S.D Agricultural University, Sardarkrushinagar -

\section{Article history}

Received: 21 Aug., 2020

Revised : 6 Nov., 2020

Accepted: 19 Dec., 2020

\section{Citation}

Patel JM, SK Patel, CR Patel, AS Patgel and KP Pachchigar. 2020. Potential of morpho- physiological traits for identification of drought tolerant bread wheat (Triticum aestivum L.) genotypes under moisture stress and irrigated environment. Journal of Cereal Research 12(3):239-246. http://doi. org/10.25174/2582-2675/2020/103826

\section{"Corresponding author}

Email:dr.jmpatel.63@gmail.com

(C) Society for Advancement of Wheat and Barley Research

\begin{abstract}
An experiment was performed to evaluate the effects of drought stress on yield, plant architecture and physiological traits in bread wheat genotypes. Field experiment was conducted with twenty genotypes at wheat research station, Vijapur, under normal and drought conditions during crop season 2017-18 and 2018-19 using randomized complete block design replicated twice under each environment. Grain yield and its attributes were recorded at Zadoks decimal scale 9, phenological traits at scale 6, plant architecture at scale 2 and 9 and physiological traits at 2, 6 and 7 scale. Significant differences for all the traits studied were found among genotypes both under normal and moisture stress conditions. For yield related traits, minimum reduction was noticed for harvest index during both the crop seasons $(0.63 \%$ and $1.88 \%)$. The values of canopy temperature was higher in stress conditions in both the crop seasons, in post anthesis stage, higher temperature in second crop cycle $(-33.93 \%)$ was observed. Among the whole panel genotypes DBW 154 and GW 510 performed well under drought stress with higher yield and harvest index. Among the tested genotypes, GW 451, DBW 154 and GW 508 were the coolest genotypes at post anthesis (CT II) but failed to maintain the grain yield under drought stress. Based on higher values of stress tolerance index, genotypes DBW 154, VL 1004, GW 510 and GW 512 were classified as drought tolerant genotypes which could be utilised in wheat improvement programme aimed at drought tolerance.
\end{abstract}

Keywords: Drought, NDVI, canopy temperature, stress tolerance index

\section{Introduction}

Wheat is extremely vulnerable to biotic and abiotic stresses and environment variation, the wide range of agro-climate condition in India under which wheat crop is grown in our country cause significant influence on end product and quality. With the continuous increase in human population wheat demand is increasing and it is expected to reach up to $40 \%$ in 2030 . However, the world's wheat consumption is expected to expand beyond production raising concerns about future food security (FAO, 2019). Drought (water deficits) and heat (high temperatures) stress are major abiotic stresses and being a yield limiting factors has become a menace for food security, under the recent and climate change scenario in future. Any further increase in the occurrence, and extremity of these stresses, either individually or in combination, would drastically affect the crop and food productivity, worldwide. In the scenario of global climate change, temperature is constantly increasing and water is depleting, thus resulting in limiting agricultural productivity. Seed filling is crucial growth stage and influenced by various metabolic processes occurring in the leaves, especially production and translocation of photo assimilates, importing precursors for biosynthesis of seed reserves, minerals and other functional constituents. 
These processes are highly sensitive to drought and heat, due to involvement of various enzymes and transporters, located in the leaves and seeds. According to the IPCC (2014) report, the decline in food productivity and quality, primarily due to rising temperatures and decreasing water tables, poses a serious threat to agriculture (IPCC, 2014; Zandalinas et al., 2018). Rodell et al., (2009) narrated that adequate water for irrigation as a result of receding water tables is also negatively impacting wheat production. Furthermore, drought tolerance and yield should be improved in parallel because farmers will not compromise to profitably produce their agricultural products under water deficit condition. This knowledge, however, could contribute to identifying agronomical and physiological traits involved in drought stress tolerance, useful for wheat genotype selection with improved performance. The present study was conducted to evaluate the effects of drought stress on wheat yield and related traits in diverse wheat accessions and to find out interrelationship among the yield, agronomic and physiological traits in drought stress and normal condition.

\section{Materials and methods}

The proposed experiment was performed to assess the effects of drought stress on yield, plant architecture and physiological traits in bread wheat genotypes. Field experiments were conducted with twenty genotypes at Vijapur, Wheat Research Station of SardarkrushinagarDantiwada Agricultural University, under irrigated and drought conditions for two years i.e. 2017-18 and 2018-19 in rabi season using randomized complete block design replicated twice at each environment. The soil texture of experimental field was loamy sand with $\mathrm{pH}$ value 7.43 and EC $0.29 \mathrm{ds} \mathrm{m}^{-1}$. Under normal irrigation ,five irrigations were provided as per standard recommendations (crown root initiation stage, late tillering stage, late jointing stage, flowering stage, and dough stage) whereas, under drought stress treatment only pre sowing irrigation was applied to ensure proper germination. In water stress experiment weeds were controlled manually (hoeing) but in irrigated experiment weeds were controlled by spraying the chemicals. During both the years no rainfall was received during the crop season and thus trial was conducted in truly drought condition. The plots consisted of 6 lines with $5 \mathrm{~m}$ in length and $20 \mathrm{~cm}$ inter-row distance. To avoid the effects of moisture on yield, 4 lines with $4 \mathrm{~m}$ in length were harvested and grain and biological yield was recorded at the time of harvesting. Standard agronomic practices were followed for raising and maintenance of the crop. Various agronomic traits evaluated were, days to heading (DH), days to maturity $(\mathrm{DM})$, plant height $(\mathrm{PH})$, spike length (SL; $\mathrm{cm}$ ), number of grains per spike (NGPS), thousand grains weight (TGW; g), grains weight per spike( GWS;g) tillers number (TIL), grains per spike (GPS) grain yield (GY; $\left.\mathrm{kg} \mathrm{plot}^{-1}\right)$, biological yield $\left(\mathrm{kg} \mathrm{plot}^{-1}\right)$, and harvest index (HI; \%). All traits were measured based on five randomly selected samples of each genotype during different stages from development stage to maturity. Days to heading and maturity were recorded as number of days from planting until $50 \%$ of the heads and physiological maturity in a plot. Grains per spike (GPS) and grain weight per spike were recorded from main spike of the five randomly selected plants. Plant height was recorded from ground to the tip of the main spike at maturity. The main spike length was measured excluding awns. For tillers number, total number of ear bearing tillers per plant were counted at the time of maturity Grain yield and biomass were calculated from $\mathrm{kg} \mathrm{plot}^{-1}$ for each genotype, Biomass was estimated from the above-ground tissues including the tillers per plant and spikes. Harvest index was calculated by dividing the grain yield by the biological yield.Canopy temperature was recorded first at anthesis stage and after 21 days of anthesis using infrared thermometer during 12-2.0 PM on clear sunny days.Normalized difference vegetation index (NDVI) was recorded two timesi.e. 15 days after germination and 21 days after anthesis using Green seeker ${ }^{\mathrm{TM}}$

\subsection{Statistical analysis}

The significance of differences between treatments was analysed using analysis of variance (ANOVA) techniques according to a randomized block design (RBD). The summary statistic and correlation among traits performed in $\mathrm{R}$ programming using mean value for each genotype. The relationship among yield and physiological traits was further explored using principal component analysis technique. Results of PCA were visualized using biplot constructed between first two principal components (PC1 and PC2) using R programming. Stress tolerance index (STI) was calculated using the following formula according to (Fernandez, 1992): 
STI $=\left(\right.$ Ysi x Ypi $/(\mathrm{Yp})^{2}$ Ysi: Yield under stress for genotype "i; Ypi: Yield under non-stress for genotype "i”; Yp : Mean of grain yield under non-stress conditions.

\section{Results and discussion}

The present investigation explores the effects of irrigated condition and drought stress on yield and physiological traits of diverse wheat germplasm. The data was collected from all four environments for two consecutive crop seasons. Ten yield and four physiological traits were investigated; the mean values vary considerably across the environments. Differences were observed in canopy temperature at anthesis and post anthesis under irrigated and drought conditions. Higher differences were observed in second cropping cycle for post anthesis canopy temperature, whereas, in both the crop cycle NDVI differences were narrow in both the treatments. Information about difference in mean values among various treatments and two cropseasons is depicted in Table 1.

\subsection{Effects of drought treatment on traits}

\section{Yield-related traits}

Among yield traits, grain yield had higher reducing effects under drought stress, as it caused $57 \%$ reductions in mean values over both the years. Six per cent higher reduction in GY was noticed in second crop season.Grain weight per spike and grains per spike was reduced by $17 \%$ and $16 \%$ respectively. SL was reduced by $10 \%$ under drought stress in which less reduction in SL was observed in second crop cycle. Harvest index recorded minimum reduction ( $0.63 \%$ in first and $1.88 \%$ (Fig.1a). in second crop season) under drought condition which was reduced in sensitive genotypes and increased in resistant genotypes under drought stress conditions indicating the importance of remobilization of photosynthates from spike to seed. Thus, among all the studied yield traits GY was severely affected by water stress. Among the whole panel genotypes DBW 154 and GW 510 performed well under drought condition with higher yield and harvest index.

\section{Phenological traits}

Days to heading and days to maturity were two phenological traits studied during the present investigation. Under water deficit condition (drought stress) days to heading and days to maturity were reduced by $7 \%$ and 13\% respectively. (Fig1b). Among both the crop cycles no significant reduction was found for both the phenological traits. Under drought stress, genotype HS 595 had maximum DH while GW 173 and GW 511 were early maturing genotypes under drought stress. As genotypes GW 510 and DBW 154 was at par in DH with early maturing genotypes and recorded minimum reduction in grain yield were favoured for further breeding. All these genotypes had least values for DTM among entire tested genotypes.

\section{Plant architecture-related traits}

Two plant architecture-related traits were included during the present study and these included plant height and tillers number. Under drought stress $\mathrm{PH}$ was reduced by $23 \%$, whereas, tillers number was reduced by $33 \%$ (Fig.1c).In second crop cycle reduction was more in tillers number whereas, no significant difference was found in plant height reduction in both the years. Among whole studied genotypes GW 509, GW 506, DBW 129 GW 505 and VL 967 undergo higher reduction for plant architecture related traits in drought stress treatment. Quaseem et al.(2019) also reported the similar findings for plant architecture traits.

\section{Physiological traits}

Physiological traits have a crucial role to determine yield, and can be used in breeding programs (Mollasadeghi et al. (2011). Two physiological traits i.e. normalized difference vegetation index (NDVI) and canopy temperature (CT) were studied among all the genotypes. The values of canopy temperature was higher in stress conditions in both the crop seasons, in post anthesis stage, higher temperature in second crop cycle (-33.93\%) was observed. These results are in agreement with the findings of Talebi (2019) and Shrivastava et al. (2017). Among the genotypes studied, VL 1004 and HS 595 had the highest value of NDVI after anthesis under drought stress. There were small but consistent differences in CT among cultivars in the well-watered treatments. Differences were observed in canopy temperature at anthesis and post anthesis under irrigated and non irrigated conditions. Among the tested genotypes, GW 451, DBW 154 and GW 508 were the coolest genotypes at postanthesis (CT II) but failed to maintain the grain yield under drought stress except DBW 154. This may be due to poor agronomic performance for ancillary traits like, number of tillers and grains per 
spike in both the years by GW 508. On an average in the year 2017-18, GW 508 produced 56 tillers per meter row length whereas, DBW 154 produced 107 tillers per meter row length which directly effect on grain yield. Secondly, number of crown roots may be less in GW 508 as indicated by less number of tillers.

Table 1: Mean values of various traits for diverse wheat genotypes grown for two crop seasons in irrigated and drought stress treatment.

\begin{tabular}{|c|c|c|c|c|c|}
\hline \multirow[t]{2}{*}{ Groups } & \multirow[t]{2}{*}{ Traits } & \multicolumn{2}{|c|}{ Irrigated } & \multicolumn{2}{|c|}{ Drought } \\
\hline & & 2017-18 & 2018-19 & 2017-18 & 2018-19 \\
\hline \multirow[t]{7}{*}{ Yield traits } & Grains per spike (n) & $53.63 \pm 4.11$ & $55.73 \pm 3.78$ & $43.25 \pm 3.58$ & $48.65 \pm 3.57$ \\
\hline & Grain weight per spike (g) & $2.19 \pm 0.22$ & $2.543 \pm 0.21$ & $1.832 \pm 0.20$ & $2.033 \pm 0.18$ \\
\hline & Spike length (cm) & $9.53 \pm 0.77$ & $9.93 \pm 0.23$ & $8.04 \pm 0.70$ & $9.43 \pm 0.40$ \\
\hline & Thousand grain weight (g) & $41.41 \pm 3.47$ & $46.14 \pm 2.48$ & $42.8 \pm 2.25$ & $43.37 \pm 2.30$ \\
\hline & Grain yield per plot $(\mathrm{kg})$ & $0.670 \pm 0.08$ & $1.467 \pm 0.07$ & $0.312 \pm 0.04$ & $0.559 \pm 0.05$ \\
\hline & Biomass yield per plot $(\mathrm{kg})$ & $2.0 \pm 0.33$ & $3.87 \pm 0.12$ & $0.921 \pm 0.10$ & $1.69 \pm 0.04$ \\
\hline & Harvest index (\%) & $34.43 \pm 2.88$ & $38.09 \pm 2.12$ & $33.27 \pm 2.19$ & $32.9 \pm 2.79$ \\
\hline \multirow[t]{2}{*}{ Phenological traits } & Days to heading (n) & $62 \pm 0.88$ & $66.73 \pm 0.73$ & $58.2 \pm 0.48$ & $61.5 \pm 0.45$ \\
\hline & Days to maturity (n) & & & & \\
\hline \multirow{2}{*}{$\begin{array}{l}\text { Plant architecture } \\
\text { related traits }\end{array}$} & Tillers per meter $(\mathrm{n})$ & $104 \pm 20.11$ & $152 \pm 18.86$ & $75 \pm 10.33$ & $88 \pm 10.39$ \\
\hline & Plant height $(\mathrm{cm})$ & $92.1 \pm 2.65$ & $99.8 \pm 1.05$ & $72.58 \pm 3.57$ & $73.97 \pm 4.21$ \\
\hline \multirow[t]{4}{*}{ Physiological traits } & NDVI-I & $0.22 \pm 0.01$ & $0.20 \pm 0.01$ & $0.23 \pm 0.01$ & $0.21 \pm 0.01$ \\
\hline & NDVI-II & $0.55 \pm 0.04$ & $0.66 \pm 0.03$ & $0.41 \pm 0.03$ & $0.34 \pm 0.06$ \\
\hline & CT-I & $22.76 \pm 0.44$ & $20.38 \pm 2.05$ & $23.46 \pm 1.19$ & $27.10 \pm 1.09$ \\
\hline & CT-II & $27 \pm 0.63$ & $19.79 \pm 1.83$ & $30.79 \pm 0.99$ & $26.28 \pm 1.13$ \\
\hline
\end{tabular}

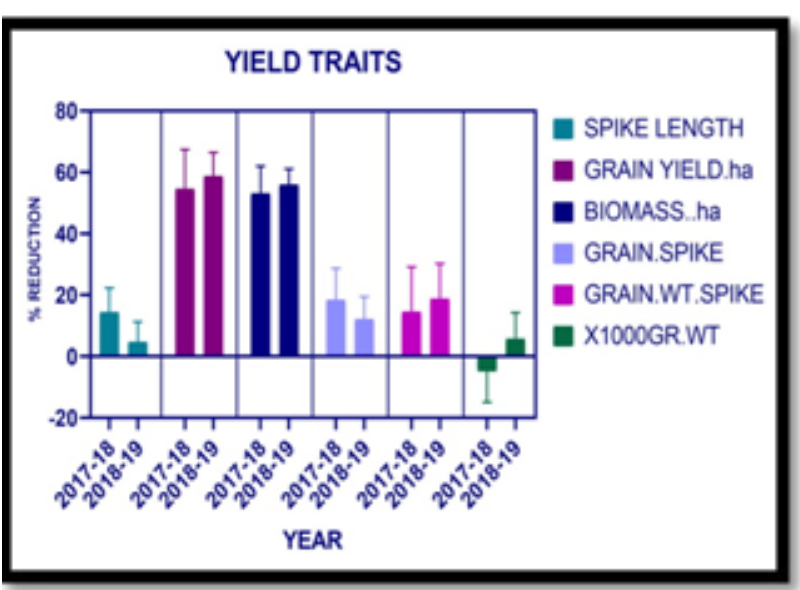

Fig. 1a Percent reduction in yield related traits of genotypes evaluated under drought stress treatment for two years.

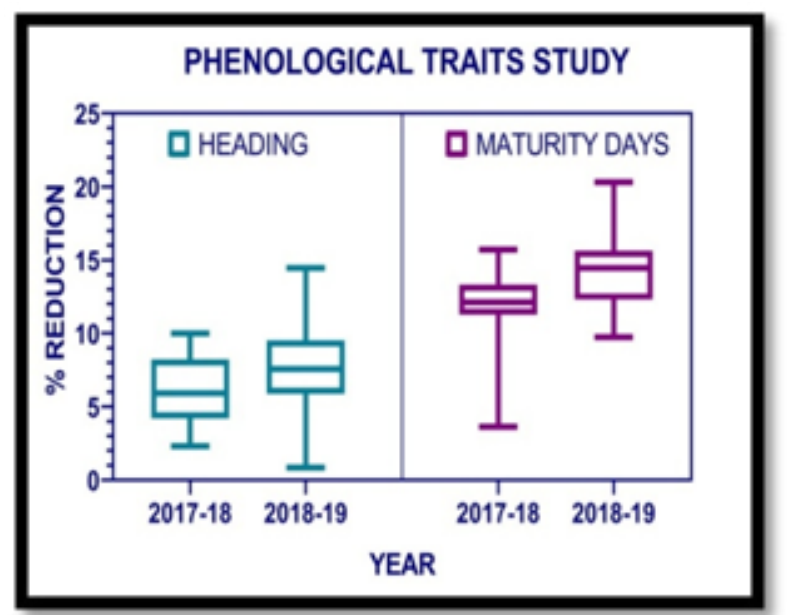

Fig. 1b Percent reduction in phenological traits of genotypes evaluated under drought stress treatment for two years. 


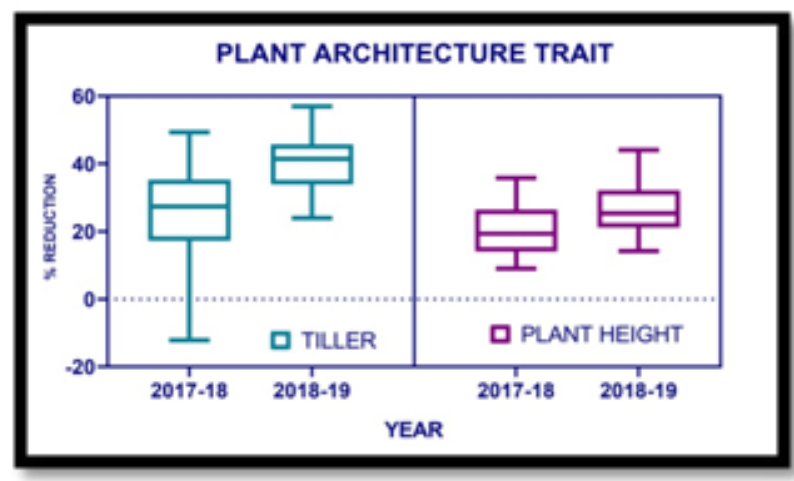

Fig.1c Percent reduction in plant architecture related traits of genotypes evaluated under drought stress treatment for two years.

\subsection{Stress tolerance index}

STI values were used for ranking of tolerant genotype, under drought stress 11 genotypes had values more than the average value of STI while 9 genotypes had values less than the average value of STI. DBW 154 has the highest value(0.59) of STI under drought

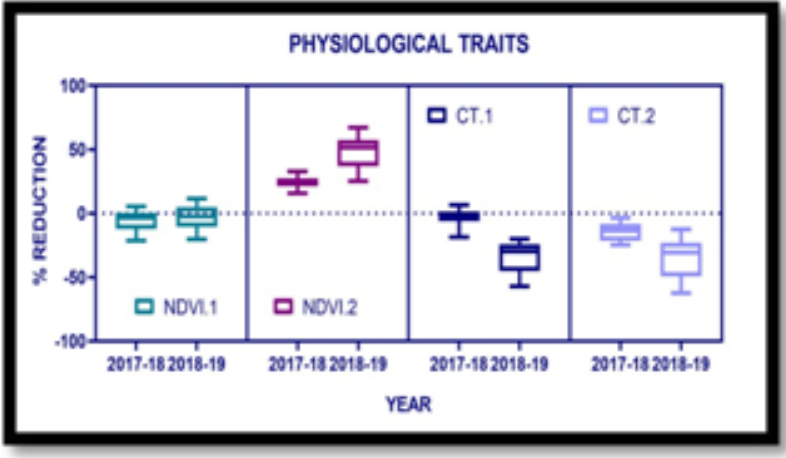

Fig.1d Percent reduction in physiological traits of genotypes evaluated under drought stress treatment for two years.

stress followed by VL 1004(0.51), GW 510(0.51) and GW 512 (0.51) (Table : 2). Based on higher values of STI genotypes DBW 154, VL 1004, GW 510 and GW 512 could be classified as drought tolerant genotypes.

Table: 2 Mean values of STI and ranking of the wheat genotypes

\begin{tabular}{|c|c|c|c|c|}
\hline Genotype & 2017-18 & 2018-19 & Mean Values of STI & Rank \\
\hline GW 505 & 0.53 & 0.44 & 0.49 & 5 \\
\hline GW 506 & 0.57 & 0.33 & 0.45 & 7 \\
\hline GW 507 & 0.43 & 0.38 & 0.41 & 13 \\
\hline GW 508 & 0.29 & 0.36 & 0.33 & 20 \\
\hline GW 509 & 0.37 & 0.33 & 0.35 & 19 \\
\hline GW 510 & 0.61 & 0.41 & 0.51 & 2 \\
\hline GW 511 & 0.42 & 0.35 & 0.39 & 16 \\
\hline GW 512 & 0.57 & 0.44 & 0.51 & 2 \\
\hline HD 3133 & 0.40 & 0.33 & 0.37 & 18 \\
\hline VL 1004 & 0.56 & 0.46 & 0.51 & 2 \\
\hline HS 595 & 0.52 & 0.32 & 0.42 & 12 \\
\hline HD 3146 & 0.49 & 0.41 & 0.45 & 7 \\
\hline HUW 677 & 0.37 & 0.50 & 0.44 & 9 \\
\hline DBW 129 & 0.26 & 0.28 & 0.27 & 21 \\
\hline VL 967 & 0.50 & 0.30 & 0.40 & 15 \\
\hline DBW 154 & 0.76 & 0.41 & 0.59 & 1 \\
\hline PBW 695 & 0.37 & 0.39 & 0.38 & 17 \\
\hline GW 451 & 0.41 & 0.41 & 0.41 & 13 \\
\hline GW 11 & 0.43 & 0.44 & 0.44 & 9 \\
\hline GW 173 & 0.55 & 0.41 & 0.48 & 6 \\
\hline Average & 0.47 & 0.39 & 0.43 & 11 \\
\hline
\end{tabular}




\subsection{Correlation Study}

Under normal condition grain yield showed strong positive correlation with thousand grain weight $(\mathrm{r}=0.48)$ whereas, under drought stress grain yield showed strong positive correlation with biomass yield $(\mathrm{r}=0.72)$ followed by tillers number (0.47)(Fig of 2) Mwadzingeni et al., (2016) also reported that tiller numbers were positively correlated with grain yield under drought stress.Under drought stress, genotypes with higher values of NDVI than overall mean at early growth stage did not end up with higher grain yield due to severe moisture stress. Thapa et al. (2020) also got the similar results after screening of wheat genotypes. Whereas, this is in discordant with the findings by Mohammed et al., (2020) suggesting potential use of NDVI to differentiate and identify superior wheat genotypes. Negative correlation between grain yield and canopy temperature was found at 21 days after anthesis under stress and non stress condition. The low canopy temperature shown by high yielding lines under stress conditions and overall negative correlation with grain yield proves that canopy temperature can be used as a measure for tolerance to stress under drought or scarce water conditions as well. Olivares-Villegas et al. (2007) also reported that canopy temperature can be used as a measure for tolerance to stress under drought conditions. Further work on molecular mapping for confirming genetic control at molecular level will give precise information about canopy temperature.

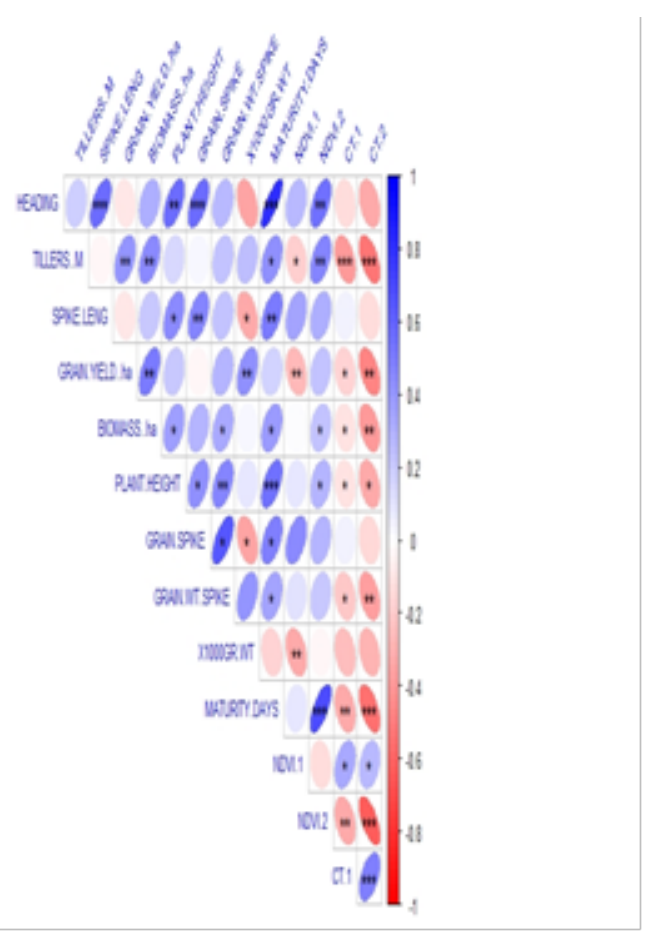

a

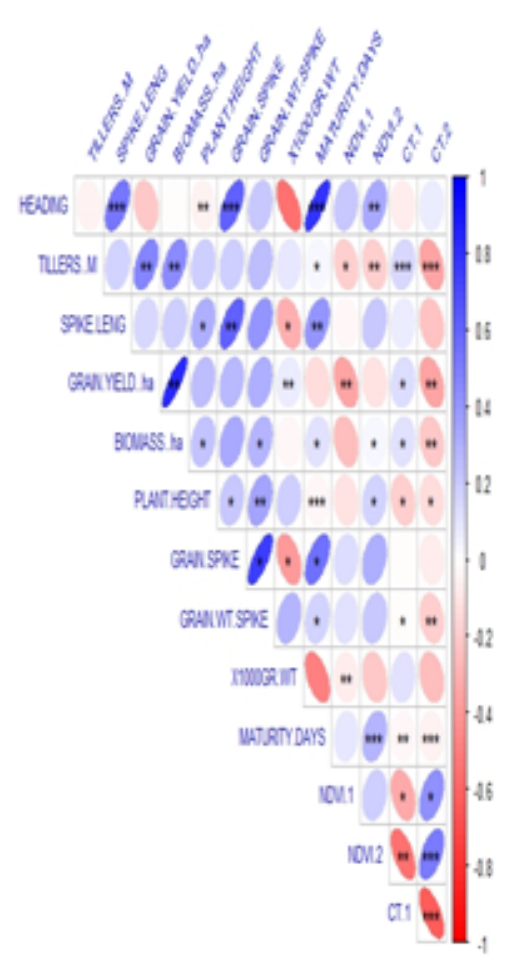

$\mathrm{b}$

Figure 2. Correlation among studied physiological and morphological traits (a) correlation among traits under non stress treatment. (b) Correlation among studied traits under drought stress. 


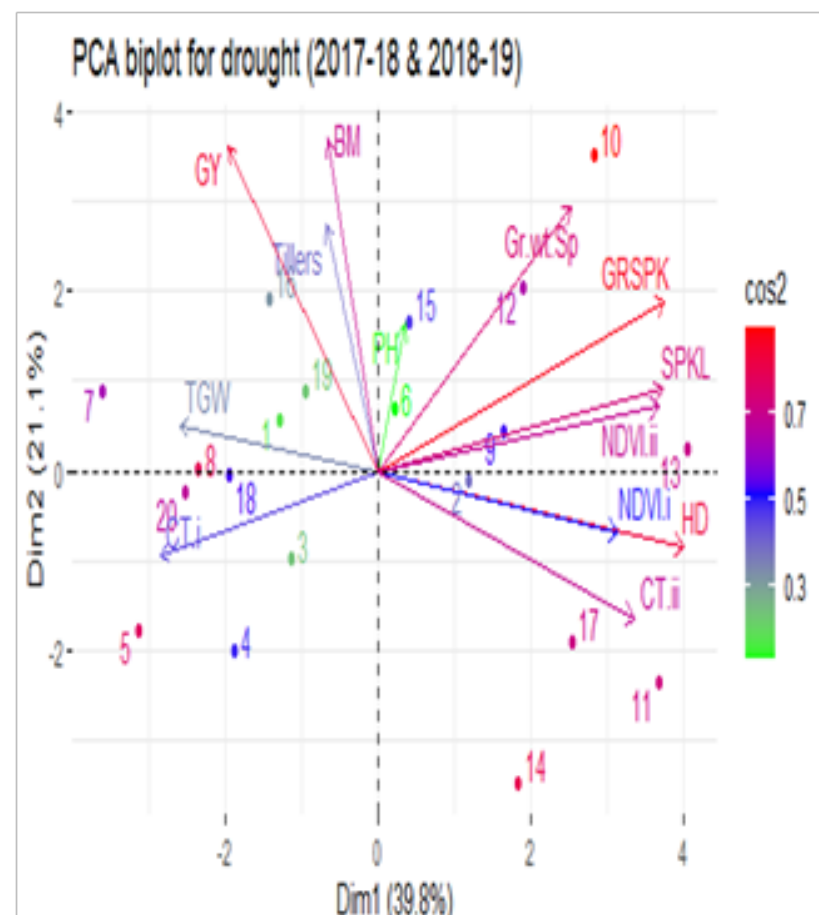

Fig.3a PCA biplot for drought (2017-18 \& 2018-19)

\subsection{Multivariate analysis}

Results from principal component analysis (PCA) demonstrated that under drought stress treatment first three PCs had eigen values more than 1 , in which first and second principal component explained 39.9 and $21.07 \%$ phenotypic variation. The major contributors to these two PCAs were GY,SPKL,DH,GPS, TIL, BM and CT II (Fig. 3a). Under non stress, first five PCs had eigenvalues more than one and first two PCs explained $41.54 \%$ and $17.16 \%$ phenotypic variation respectively. The major contributors to the first two components under drought stress were GY, DH, GWS and GPS (Fig. 3b). Results of principle component analysis for GY, TIL,

\section{References}

1. Fernandez GCJ. 1992. Effective selection criteria for assessing plant stress tolerance. In: Kuo, CG (eds). proc. Sympos. Asaptation of vegetative and other food crops to temperature and water stress. Shanhua Taiwan. 13-18 Aug, pp. 257-70.

2. Food and Agriculture Organization of the United Nations (FAO). 2019. World food situation. Available at: http://www.fao.org/worldfoodsituation/csdb/en/ https://doi.org/10.1038/s41598-019-43477-z

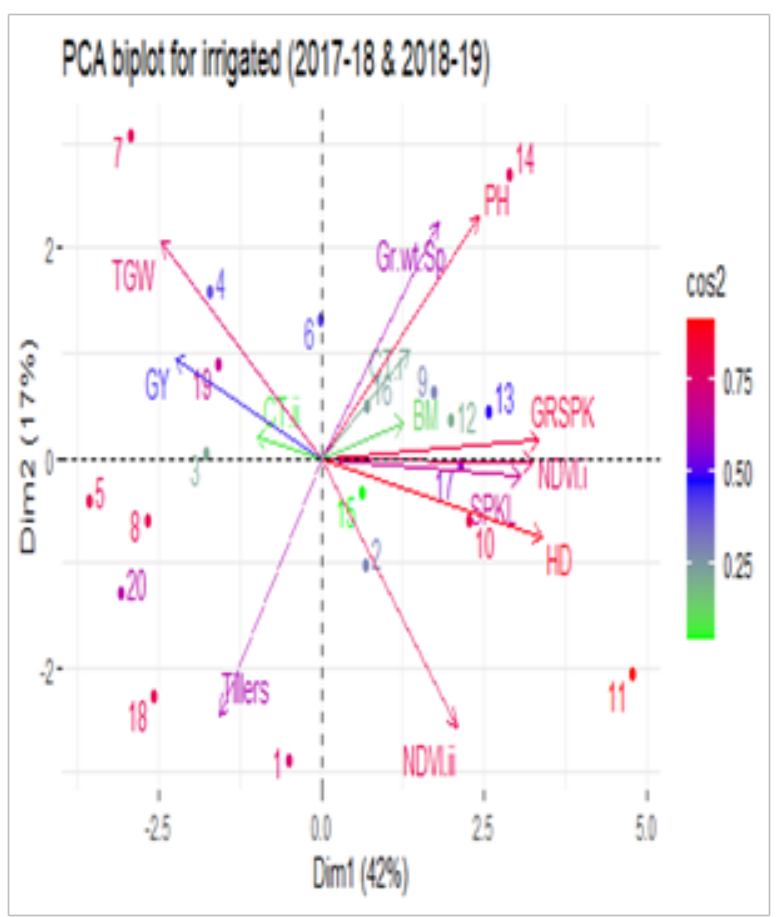

Fig.3b PCA biplot for irrigated (2017-18 \& 2018-19)

SPKL and CT II were in accordance with the findings of Quaseem et al.(2019).The principal component analysis highlighted many of the included physiological and plant related traits as prevailing descriptive variables of yield and its components variations, signifying their utility for cultivar screening. Improvement of trait having a major contribution in the first two components may lead to improved varieties with drought stress tolerance. Further studies involving more diverse genotypes and years to validate the potential power of the stated selection markers for moisture-stressed wheat.

3. IPCC 2014. Climate change synthesis report contribution of working groups I. II and III to the fifth assessment report of the intergovernmental panel on climate change. Geneva: IPCC, 151.

4. Mohammed A, Naser, Raj Khosla, Louis Longchamps and Subash Dahal. 2020. Using NDVI to differentiate wheat genotypes productivity under dryland and irrigated conditions. Remote Sensing 12(5), 824; https://doi.org/10.3390/rs12050824. 
5. Mollasadeghi V, AA Imani, R Shahryari and M Khayatnezhad. 2011. Classifying bread wheat genotypes by multivariable statistical analysis to achieve high yield under after anthesis drought. Middle-East Journal of Scientific Research 7: 217-220.

6. Mwadzingeni L, H Shimelis, S Tesfay and TJ Tsilo. 2016 Screening of bread wheat genotypes for drought tolerance using phenotypic and proline analyses. Frontiers in Plant Science 7: 1276. doi: 10.3389/ fpls.2016.01276

7. Olivares-Villegas JJ, MP Reynolds and GK McDonald. 2007. Drought-adaptive attributes in the Seri/Babaxhexaploid wheat population. Functional Plant Biology 34: 189-203.

8. Qaseem MF, R Qureshi and H Shaheen. 2019. Effects of pre-anthesis drought, heat and their combination on the growth, yield and physiology of diverse wheat (Triticum aestivum L.) genotypes varying in sensitivity to heat and drought stress. Scientific Reports 9: 6955. https://doi.org/10.1038/s41598-019- 43477-z

9. Matthew R, Isabella Velicogna and JS Famiglietti.
2009. Satellite-based estimates of groundwater depletion in India Nature DOI: 10.1038/nature08238

10. Srivastava A, P Srivastava, A Sharma and RS Sarlach. 2017. Canopy temperature an effective measure of drought stress tolerance in RIL Population of Wheat. Vegetos 30:1

11. Thapa S, C Jackie, Rudd, X Qingwu, M Bhandari, K Srirama, Reddy, EJ Kirk, L Shuyu, NR Devkota, J Baker and S Baker. 2019. Use of NDVI for characterizing winter wheat response to water stress in a semi-arid environment, Journal of Crop Improvement 33(5): 633-648

12. Talebi R, N Baghebani, E Karami and MH Ensafi. 2019. Defining selection indices for drought tolerance in chickpea under terminal drought stresses. Journal of Applied Biological Sciences 5(3): 33-38.

13. Zandalinas SI, R Mittler, D Balfagón, V Arbona and A Gómez-Cadenas. 2018. Plant adaptations to the combination of drought and high temperatures. Physiology Plant 162: 2-12. doi: 10.1111/ppl.12540 